Journal of

Accident and

Emergency

Medicine 1995

12, 138-142
Correspondence: Rob J. Edwards, Staff Specialist, Department of Emergency Medicine, Westmead Hospital, CNR Hawkesbury Road \& Darcy Street, Westmead, NSW 2145, Australia

CASE REPORT

\title{
Extreme methaemoglobinaemia secondary to recreational use of amyl nitrite
}

\author{
R.J. EDWARDS \& J. UJMA
}

Department of Emergency Medicine, Westmead Hospital, Westmead, New South Wales, Australia

\section{INTRODUCTION}

Haemoglobin is continuously oxidized from the ferrous $\left(\mathrm{Fe}^{2+}\right)$ to the ferric $\left(\mathrm{Fe}^{3+}\right)$ form and reduced back again. The ferric $\left(\mathrm{Fe}^{3+}\right)$ form, termed methaemoglobin (MetHb), is incapable of transporting oxygen. In the normal physiological state the concentration of methaemoglobin is less than 1\%. Figure 1 illustrates the physiological reactions responsible for the reduction of MetHb back to $\mathrm{Hb}$. It is reported that MetHb levels of 10 $25 \%$ produce cyanosis, $35-40 \%$ produce mild symptoms (e.g. dyspnoea), levels of $60 \%$ produce lethargy and coma and levels of $70 \%$ or more are lethal. ${ }^{2.3}$ A case of extreme, life-threatening methaemoglobinaemia due to the recreational use of amyl (isobutyl) nitrite is presented. No case has been found in the literature where the MetHb level was so high.

Key words: amyl nitrate, methaemoglobinaemia, methylene blue

\section{CASE REPORT}

A 44-year-old man was brought by ambulance to St Vincent's Hospital Emergency Department at 23.37 hours. The patient had been found in the steam room of a bathhouse, unconscious, blue and lying in a pool of vomitus. There was an empty bottle of amyl (isobutyl) nitrite next to him, and workers at the establishment stated that he had 'consumed' large amounts of amyl nitrite.

On arrival of the paramedics, the patient was hypoventilating, hypotensive, unresponsive to pain and had poor skin colour. There was no response to $2 \mathrm{mg}$ of naloxone, administered intravenously. The patient was intubated endotracheally by the paramedics, given $100 \%$ oxygen, ventilated manually and transported to hospital.

On arrival at the Emergency Department his skin was noted to be a deep charcoal grey colour, despite the fact that he was receiving $100 \%$ oxygen and having good air entry into both lungfields on
Major pathway (handles $95 \%$ of metHb. under physiological conditions)

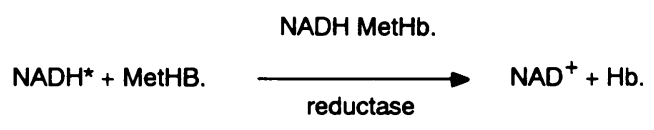

Pathway activated by methylene blue 20

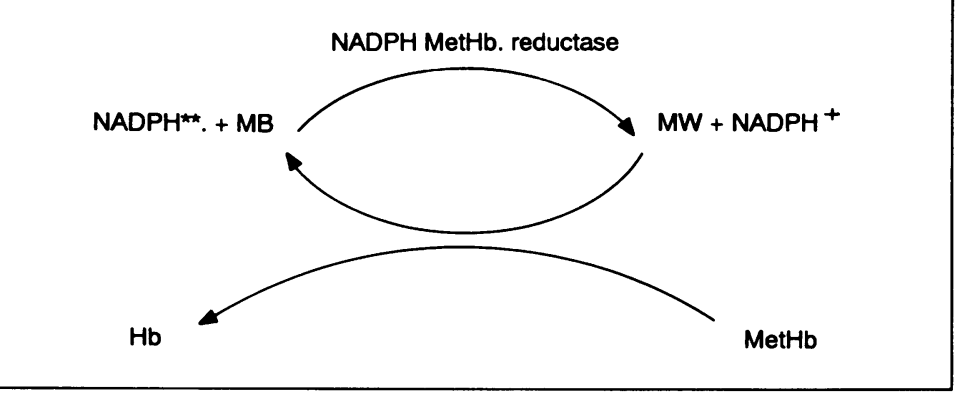

Fig. 1. Mechanisms for reduction of methaemoglobin. MB, methylene blue; MW, methylene white; *Embden-Meyerhoff pathway is the major source of NADH in red blood cells; **hexose mono-phosphate shunt is the major source of NADPH. G6PD is required for its production. 
R.J. Edwards et al. auscultation. His systolic blood pressure was 70 $\mathrm{mmHg}$, and his pulse was 60 beats $\mathrm{min}^{-1}$. He was unresponsive to pain, and his pupils were constricted, equal and fixed.

Arterial and venous samples were drawn for arterial blood gas (ABG) analysis, MetHb, full blood count (FBC), and determination of electrolytes, urea and creatinine levels.

However, 12 min after arrival the patient suffered a bradycardic arrest, requiring cardio-pulmonary resuscitation and $2 \mathrm{mg}$ adrenaline, administered intravenously. He regained a cardiac output after 30 s. The patient's MetHb level was $94 \%(n<1.5 \%)$ and he was given $80 \mathrm{mg}$ (c.1 $\mathrm{mg} \mathrm{kg}^{-1}$ ) of tetramethylthionine (methylene blue) intravenously over a period of $10 \mathrm{~min}$. Twenty minutes after administration of the methylene blue, the patient's colour had improved slightly and there was a return of spontaneous respiration, but he remained unresponsive to pain.

Further physical examination revealed a core temperature of $32.5^{\circ} \mathrm{C}$ (per rectum). There were no focal neurological signs, and the systolic blood pressure remained low $(70 \mathrm{mmHg})$. The abdomen was soft and not distended. There was no sign of trauma, and no other abnormality was found.

The results of initial investigations were as follows (ranges in parenthesis): $\mathrm{ABG}\left(\mathrm{FiO}_{2}=1\right) \mathrm{pH}$ 7.17, (7.35-7.45); $\mathrm{Po}_{2}$, unable to be measured due to technical problems; $\mathrm{PCO}_{2}, 39 \mathrm{mmHg}(32-45)$; $\mathrm{HCO}_{3}, 14 \mathrm{mmol} \mathrm{L}^{-1}$ (24-31); and base excess (B.E.) $-14(-3-+3)$. Chest radiograph was normal. A 12lead electrocardiograph showed sinus rhythm, rate 98 beats min $^{-1}$ with ST elevation (concave down) in leads $\mathrm{V} 1-\mathrm{V} 6$. $\mathrm{Hb}$ was $13.1 \mathrm{~g} \mathrm{dL}^{-1}$ (13.0-18.0), WCC was $9.7 \times 10^{9} \mathrm{~L}^{-1}(4.0-11.0)$, and platelet count was $211 \times 10^{9}(150-400)$. Blood alcohol level was $0.15 \%$.

A repeat MetHb measurement gave a value of $26 \%$. The patient was given another $100 \mathrm{mg}$ of methylene blue at this time. A further $50 \mathrm{~mL}$ of $8.4 \%$ sodium bicarbonate were administered for a persisting metabolic acidosis $\left(\mathrm{pH}, 7.05 ; \mathrm{PCO}_{2}, 46\right.$; $\mathrm{Po}_{2}$, could not be measured; $\mathrm{HCO}_{3}, 13$; B.E., -19).

By 06.00 hours, the patient's colour was pink. A repeat MetHb level was $1.6 \%$ at 09.30 hours. At this time the patient was opening his eyes to speech and obeying commands. He continued to improve and was extubated at 18.00 hours. He was confused initially, but his sensorium had cleared by the next morning. He remembered no details from the night of his overdose. Thirty-six hours after therapy unit to the ward.

It was decided to keep the patient in hospital and monitor him for haemolytic anaemia. However, the patient discharged himself, against medical advice, on day 5 . There was no evidence of anaemia at this time, and he showed no evidence of any residual neurological deficit on clinical testing. Total creatinine phosphokinase (CPK) levels 12 and $36 \mathrm{~h}$ after admission were 385 and $681 \cup L^{-1}$, respectively $\left(<130 \mathrm{U} \mathrm{L}^{-1}\right)$. The MB fractions at these times were 24 and $25 U L^{-1}$, respectively (<15 $\left.U L^{-1}\right)$. A repeat ECG before discharge was normal. Clinically, the patient had made a complete, uncomplicated recovery. Further follow-up was performed by the patient's local medical officer. The patient refused counselling from the drug and alcohol service.

We note that the patient presented again to our Emergency Department 6 months later with chest pain after injecting cocaine intravenously. ECG on this occasion was normal, and he was discharged for follow-up with his local medical officer.

\section{DISCUSSION}

Although rare, it is important to diagnose methaemoglobinaemia when it presents because it is potentially fatal and yet readily treated. A clue to the diagnosis is the appearance of chocolate brown blood upon venesection or arterial sampling. ${ }^{1.4,14}$ The diagnosis can be confirmed by spectrophotometric analysis of the patient's blood, giving a MetHb level expressed as a percentage of the total $\mathrm{Hb}$ level. The blood should be analysed very soon after being drawn, as the MetHb level in the sample will decrease with time. ${ }^{36}$

\section{Aetiology}

Table 1 lists the agents that most commonly cause acquired methaemoglobinaemia. It has been reported that ingestion of nitrites is not dangerous because they are degraded in the GIT. ${ }^{41}$ However, there are many case reports of severe, sometimes fatal, methaemoglobinaemia resulting from ingestion of isobutyl nitrite..$^{3.16 .19,20}$

\section{Management of acquired methaemoglobinaemia}

After ensuring and protecting the airway, providing appropriate respiratory and cardiovascular support and decontamination (e.g., removing soiled clothing or decontaminating oxidants in the gut), tetramethylthionine (methylene blue, MB) should 
Extreme

methaemoglo-

binaemia

secondary to

recreational use of

amyl nitrite

Table 1. Agents most commonly implicated in acquired methaemoglobinaemia

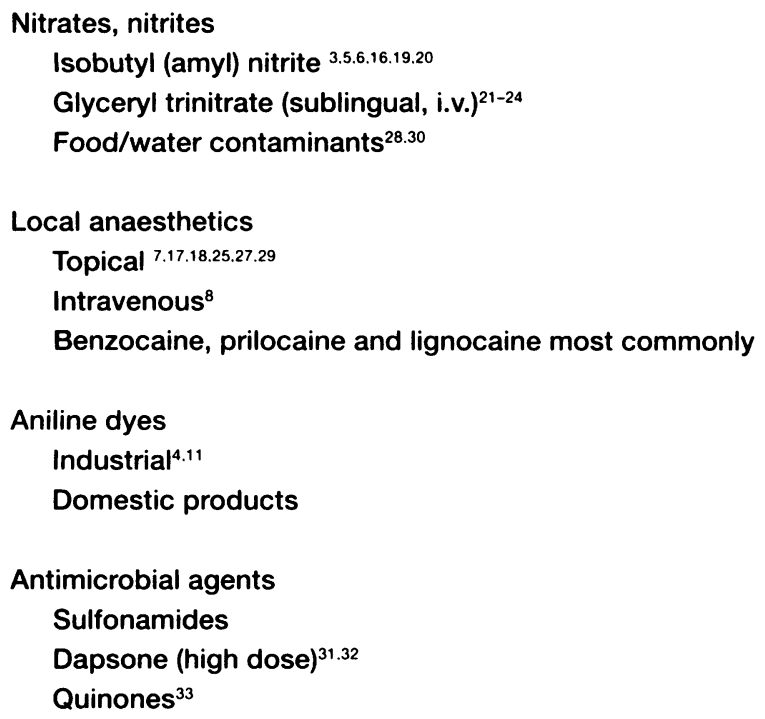

be used early on if it is indicated. Figure 1 shows its mechanism of action.

Accepted indications for MB are a MetHb level of $>30-40 \%$, or a situation where the patient is symptomatic or anaemic, regardless of the MetHb level. ${ }^{2.4}$ The clinician must be careful to treat each case individually according to the clinical indicators of severity (e.g., level of consciousness, dyspnoea, myocardial ischaemia), as some patients have died $^{1.16}$ or have been severely symptomatic ${ }^{17}$ with MetHb levels under $35 \%$, while other patients have recovered with levels above $80 \% . .^{14.18}$ The initial dose is $1-2 \mathrm{mg} \mathrm{kgh}^{-1}$ body weight, administered intravenously over 5 min..$^{2.4 .9}$ Significant clinical improvement and a substantial reduction in the MetHb level usually occur within 30-60 min. In cases where repeat doses of MB are required, concern may be caused by the fact that MB itself has a direct oxidant effect on $\mathrm{Hb} .^{9}$ This effect is likely to be more marked in the following conditions:

(1) NADPH methaemoglobin reductase deficiency (see Fig. 1);

(2) G6PD deficiency;

(3) large doses of $\mathrm{MB}$ (> $7 \mathrm{mg} \mathrm{kg}^{-1}$ ).

If a patient has a known deficiency of one of the above enzymes, or there is failure of an adequate dose of MB (up to $7 \mathrm{mg} \mathrm{kg}^{-1}$ ) to reduce the MetHb level and produce a clinical improvement, ${ }^{34-36}$ then alternative or additional treatment with an exchange transfusion should be considered. Apart from the above situations, MB should not be withheld if the indications for its use and reuse are present. This is because the methaemoglobinproducing effects of $\mathrm{MB}$ in vivo are small, ${ }^{10.11}$ and are dominated by the methaemoglobin-reducing effects. Table 2 lists the reasons why acquired methaemoglobinaemia may fail to respond to $\mathrm{MB}$.

Methylene blue, especially at doses of $7 \mathrm{mg} \mathrm{kg}^{-1}$, may cause a sensation of dyspnoea, pressure on the chest, restlessness, excitation, apprehension, a feeling of impending death, tremor, nausea and vomiting. ${ }^{34}$

Persistent cyanosis after treatment of acquired methamoglobinaemia with MB may be due to an insufficient dose of methylene blue, failure to respond to methylene blue (see Table 2), or blue discoloration of the skin and mucous membranes caused by the methylene blue itself. The latter may occur, despite the correction of methaemoglobinaemia. ${ }^{12}$ Thus a repeat MetHb level should be obtained before readministering methylene blue

Table 2. Reasons for failure of methaemoglobinaemia to respond to methylene blue 
R.J. Edwards et al. simply because the patient is still 'blue'.

\section{Use of pulse oximetry}

Both the condition and the cure cause aberrations in pulse oximetry. Because MB absorbs light at a peak of $668 \mathrm{~nm}$, a similar wavelength to reduced $\mathrm{HB}, \mathrm{MB}$ is mistaken for reduced $\mathrm{Hb}$ by the oximeter, thus giving a spuriously low result for oxygen saturation. ${ }^{13}$ Methaemoglobin, which has a maximal light absorption at a wavelength similar to oxyhaemoglobin, $660 \mathrm{~nm}$, is therefore mistaken for oxyhaemoglobin and oximeter overestimates oxygen saturation. ${ }^{15}$

\section{Exchange transfusion}

Exchange transfusion has been used the treatment of acquired methaemoglobinaemia both in children ${ }^{18.35 .37-39}$ and in adults. ${ }^{32.36 .40}$ Exchange transfusion is of therapeutic benefit where acquired methaemoglobinaemia has failed to respond to MB (see Table 2), ${ }^{35.36}$ where the clinical condition is so severe that additional treatment to $\mathrm{MB}$ may be helpful, ${ }^{18.40}$ or where the recommended dose of MB has been reached and the patient still has significant methaemoglobinaemia. ${ }^{32}$

\section{REFERENCES}

1. Gowans W.J. (1990) Fatal methaemoglobinaemia in a dental nurse. A case of sodium nitrite poisoning. British Journal of General Practice 40, 470-471.

2. Wintrobe M.M., Less G.R., Boggs I.R. et al. (1974) Clinical Haematology, 7th edition. Lea \& Febiger, Philadelphia (1991).

3. Forsyth R.J. \& Moulden A. (1991) Methemoglobinemia after ingestion of amyl nitrite. Archives of Disease in Childhood 66, 152.

4. Phillips D.M., Gradisek R. \& Heiselman D.E. Methemoglobinaemia secondary to aniline exposure. Annals of Emergency Medicine 19, 425-429.

5. Laaban J.P., Boopenen P. \& Rochemaure J. (1985) Amyl nitrate poppers and methemoglobinaemia. Annals of Internal Medicine 103, 804.

6. Pierce J.M. \& Nielsen M.S. (1989) Acute acquired methaemoglobinaemia after amyl nitrite poisoning. British Medical Jornal 298, 1566.

7. Anderson S.T., Hajducek J. \& Barker S.J. (1988) Benzocaine induced methaemoglobinaemia in an adult: accuracy of pulse oximetry with methaemoglobinaemia. Anesthetics and Analgesics. 67, 10991101.
Emergency Medicine 16, 323-325.

9. Bodansky. (1951) Methaemoglobinaemia and methaemoglobin producing compounds. Pharmacological Review. 3, 144-196.

10. Smith R.P. \& Thron C.D. (1972) Hemoglobin, methylene blue and oxygen interactions in human red cells. Journal of Pharmacological and Experimental Therapeutics, 183, 549-558.

11. Harvey J.W. \& Keith A.S. (1983) Studies of efficacy of methylene blue therapy in aniline induced methaemoglobinaemia. British Journal of Haematology 54, 29-41.

12. Goluboff N. \& Wheaton R. (1961) Methylene blue induced cyanosis and acute haemolytic anaemia complicating treatment of methaemoglobinaemia. Journal of Paediatrics 58, 86-90.

13. Kessler M.R., Eide T. \& Humayan B. (1986) Spurious pulse oximeter desaturations with methylene blue injection. Anesthesiology 65, 435-436.

14. Caudil L., Walbridge J. \& Kuhn G. (1990) Methaemoglobinaemia as a cause of coma. Annals of Emergency Medicine 19, 677-679.

15. Reider H.U., Frei F.J., Zbinden A.M. et al. (1989) Pulse oximetry in methaemoglobinaemia. Failure to detect low oxygen saturation. Anaesthesia 44, 326-327.

16. Shesser R., Dixon D., Allen Y.et al. (1980) Fatal methemoglobinaemia from butyl nitrite ingestion. Annals of Internal Medicine 92, 131-132.

17. Sandza J.C., Roberts R.W., Shaw R. C. et al. (1980) Symptomatic methemoglobinemia with a commonly used topical anesthetic, cetacaine. Annals of Thoracic Surgery 30, 187-190.

18. Kellet P.B. \& Copeland C.S. (1983) Methemoglobinemia associated with benzocaine containing lubricant. Anesthesiology 59, 463-464.

19. Steiner R.W. \& Manoguerra A.S. (1980) Butyl nitrite and methemoglobinamia. Annals of Internal Medicine 92, 570.

20. Wason S., Destky A.S., Platt O.S. et al. (1980) Isobutyl nitrite toxicity by ingestion. Annals of Internal Medicine 92, 637-638.

21. Fibuch E.E., Cecil W.T. \& Reed W.A. (1979) Methemoglobinaemia associated with organic nitrite therapy. Anesthetics and Analgesics. 58, 521-523.

22. Gibson G.R., Hunter J.B., Raabe R.S. et al. (1982) Methemoglobinemia produced by high dose intravenous nitroglycerin. Annals of Internal Medicine 96, 615.

23. Zurick A.M., Wagner R.H., Starr N.J. et al. (1984) Intravenous nitroglycerin, methemoglobinemia and respiratory distress in a post operative cardiac surgical patient. Anesthesiology 61, 464-466.

24. Robiscek F. (1985) Acute methemoglobinemia during cardiopulmonary bypass caused by intravenous nitroglycerin infusion. Journal of Thoracic and Cardiovascular Surgery 90, 931-934.

25. O'Donohue W.J., Moss L.M. \& Angelillo V.A. (1980) 
Extreme

methaemoglo-

binaemia

secondary to

recreational use of

amyl nitrite
Acute methemoglobinemia by topical benzocaine and lignocaine. Archives of Internal Medicine 140, 1508-1509.

26. Ludwig S.L. (1981) Acute toxic methemoglobinemia following dental analgesia. Annals of Emergency Medicine 10, 261-266.

27. Jakobson B. \& Nilsson A. (1985) Methemoglobinemia associated with a prilocainelidocaine cream and trimethoprim-sulfamethoxazole. A case report. Acta Anesthesiologica Scandinavica 29, 453-455.

28. MacKenzie A. (1984) An unusual cause of poisoning (letter). Medical Journal of Australia 141, 903.

29. Siebert R.W. \& Siebert J.J. (1984) Infantile methemoglobinemia induced by a topical anesthetic, cetaciane. Laryngoscope, 94, 816-817.

30. Walley T. \& Flanagan M. (1987) Nitrite induced methaemoglobinaemia. Postgraduate Medical Journal 63, 643-644.

31. Reiter W.M. \& Cinoch P.J. (1987) Dapsone induced methemoglobinemia in a patient with pneumocystis carinii pneumonia and AIDS (letter). New England Journal of Medicine 317, 1740-1741.

32. Berlin G., Brod A.B., Hilden J.O. et al. (1984) Acute dapsone intoxication: a case treated with continuous infusion of methylene blue, forced diuresis and plasma exchange. Clinical Toxicology 22, 537-548.

33. Goldfrank L.R., Flomenbaum N.E., Lewin N.A. et al. (1990) Toxicologic Emergencies, 4th edition.
Appleton Lange, New York.

34. Rosen P.L., Johnson C. \& McGehee W.G. (1971) Failure of methylene blue in toxic methaemoglobinaemia. Association with glucose-6-phosphate dehydrogenase deficiency. Annals of Internal Medicine 75, 83-86.

35. Mier R.J. (1988) Treatment of aniline poisoning with exchange transfusion. Clinical Toxicology. 26, 357364.

36. Schimelman M.A., Soler J.M. \& Muller H.A. (1978) Methemoglobinemia: nitrobenzene ingestion. Journal of the American College of Emergency Physicians 7, 406-408.

37. Ewing M.C. \& Mayon-White R.M. (1951) Cyanosis in infancy from nitrates in drinking water. Lancet 00 , 931-934.

38. Lebowitz R.L. Intravesical chemical cauterization and methaemoglobinaemia. Paediatrics 65, 630.

39. Bruton O.C. (1958) Exchange transfusion for acute poisoning in children. United States Armed Forces Medical Journal, 9, 1128-1131.

40. Harris J.O., Rumack B.H., Peterson R.G. et al. (1979) Methemoglobinemia resulting from absorption of nitrates Journal of the American Medical Association 242, 2869-2871.

41. Nickerson M., Parker J.O., Lowry T.P. et al. (1979) Isobutyl Nitrite and Related Compounds. San Franco Pharmex Ltd, San Francisco. 